\title{
Kinerja Algoritma Kmeans++ Pada Pengelompokkan Dokumen Teks Pendek pada Abstrak di Jurusan Teknik Elektro Fakultas Teknik UNJ
}

\author{
Catur Rahma Sistiani, Widodo ${ }^{2}$, Bambang Prasetya Adhi ${ }^{3}$
}

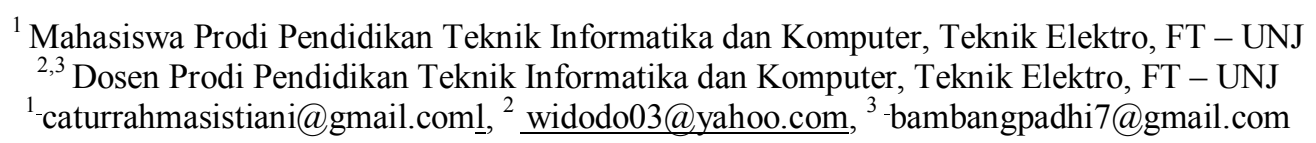

\begin{abstract}
Abstrak
Pengelompokkan pada dokumen teks pendek masih sulit ini dikarenakan di sparsity kata. Tujuan penelitian ini adalah untuk mengetahui kinerja algoritma k-means++ pada teks pendek dan untuk mengetahui proses pengelompokkan algoritma k-means ++ pada teks pendek di abstrak skripsi Jurusan Teknik Elektro Fakultas Teknik UNJ dilaksanakan pada semester genap tahun ajaran 2014-2015. Penelitian ini menggunakan metode penelitian eksperimen. Data abstrak yang digunakan sebanyak 200 abstrak. Penelitian meneliti 4 data yaitu Data pertama adalah abstrak ilmiah di jurusan Teknik Elektro, Universitas Negri Jakarta pada paragraf 1 sampai paragraf 3. Data kedua adalah paragraf 1 pada abstrak ilmiah di jurusan Teknik Elektro, Universitas Negri Jakarta. Data ketiga adalah paragraf 2 pada abstrak ilmiah di jurusan Teknik Elektro, Universitas Negri Jakarta. Data keempat adalah paragraf 3 pada abstrak ilmiah di jurusan Teknik Elektro, Universitas Negri Jakarta. Pengujian kinerja algoritma k-means++ menggunakan matrix confusion. Berdasarkan hasil penelitian, didapatkan kesimpulan bahwa keakurasian pada abstrak, paragraf 1 di abstrak, paragraf 2 di abstrak, dan paragraf 3 di abstrak mencapai lebih dari 80\%. Didapatkan juga kesesuaian antar data yang diprediksi dengan hasil yang benar dari data yang sebenarnya(presisi) pada abstrak, paragraf $1 \mathrm{di}$ abstrak, paragraf $2 \mathrm{di}$ abstrak, dan paragraf $3 \mathrm{di}$ abstrak mencapai lebih dari 50\% . Didapatkan juga peluang munculnya data relevan yang diambil sesuai dengan query (recall) pada abstrak, paragraf 1 di abstrak, paragraf 2 di abstrak, dan paragraf 3 di abstrak mencapai lebih dari $80 \%$.
\end{abstract}

Kata kunci : Algoritma kmenas++, Teks Pendek, Matrix Confusion

\section{Pendahuluan}

Banyaknya dokumen teks yang tersimpan dalam komputer membuat pencarian informasi menjadi sulit. Clustering menjadi salah satu solusi untuk mengelompokkan dokumen yang berjumlah besar sehingga membantu proses pencarian informasi yang dibutuhkan.

Clustering ini adalah metode pengelompokkan data yang menemukan kelompoknya berdasarkan kemiripan atau kesamaan secara natural. Ada banyak sekali macam-macam clustering contohnya algoritma k-means yang paling banyak dikenal, mudah diterapkan dan juga algoritma k-means menjadi salah satu 10 top algoritma pada data mining menurut IEEE ICDM pada tahun 2006. Tetapi k-means ini mempunyai kekurangan yang sangat tergantung dengan kondisi inisialisasi awal clustering. Pada algoritma k-means, pemilihan kondisi inisialisasi awal di lakukan secara acak, jika inisialisasi kurang baik, maka waktu proses pengelompokkan yang dihasilkan pun menjadi kurang optimal. maka algoritma kmeans ini perlu pengembangan untuk inisialisasi pada cluster awal.

Pada tahun 2007 David Arthur dan Sergei Vassilvitskii mengembangkan algoritma kmeans ++ untuk mengatasi masalah kekurangan pada proses pengelompokkan yang kurang optimal, yang terdapat pada algoritma k-means. 
Tipe teks yang berjenis teks panjang mudah saat proses pengelompokannya dan sering digunakan untuk penelitian, tetapi pengelompokkan untuk teks pendek masih jarang. Pengelompokkan teks pendek masih dianggap sulit secara statistik dan teks pendek ini mempunyai masalah di sparsity (keterbatasan) kata-kata dan teks pendek ini mengandung tidak lebih dari 100 kata.

\section{Clustering}

Menurut Berkhin, Pavel diacu dalam Sri Andayani (2007), clustering adalah membagi data ke dalam group-group yang mempunyai obyek yang karakteristiknya sama. Menurut Garcia-Molina Et al., diacu dalam Sri Andayani (2007), clustering adalah mengelompokkan item data ke dalam sejumlah kecil grup sedemikian sehingga masing-Masing grup mempunyai sesuatu persamaan yang esensial. Clustering adalah pengelompokkan objek yang mirip satu sama lain dan objek yang berbeda tergabung dengan kelompok lain (Max Bramer,2007). Berdasarkan definisi di atas dapat disimpulkan bahwa clustering adalah pengelompokkan data yang menemukan kelompokkannya dengan karakteristik yang sama dan objek yang berbeda akan tergabung dengan kelompok yang lain.

\section{Algoritma kmeans++}

Metode clustering ada banyak salah satunya adalah k-means ++ , telah dikembangkan dari algoritma k-means di mana salah satu metode clustering menggunakan pendekatan yang didasari pada partisi (D.Arthur,2007). K-means menentukan nilai awal centroid secara acak yang kadang-kadang memerlukan waktu pemrosesan lebih lama. Oleh karena itu, kmeans++ digunakan untuk mengurangi kelemahan k-means dari pemrosesan waktu yang lama. Algoritma k-means++ merupakan algoritma pengelompokan secara partisi yang merupakan pengembangan dari algoritma kmeans (Wayan Surya Prianta,dkk., 2011). Berdasarkan pendapat beberapa ahli di atas, dapat di simpulkan bahwa k-means ++ adalah pengembangan dari algoritma kmeans untuk mengurangi kelemahan k-means yang kadangkadang memerlukan waktu pemrosesan clustering lebih lama. Berikut ini adalah algoritma k-means++

1. Menentukan satu centroid awal pada seluruh data dokumen secara acak

2. Tambahkan sebuah center baru $c_{i}$ dari semua data yang belum terpilih sebagai centroid, dengan menggunakan weighted propability distribution dimana data yang dipilih dengan probabilitas tertinggi dengan menggunakan rumus : $\frac{D(x)^{2}}{\sum x \in X^{D(x)^{2}}}$
3. Ulang langkah ke 2, hingga sejumlah $k$ centroids telah terpilih

4. Lalu di lanjutkan dengan algoritma KMeans, yaitu

A. Hitung jarak antar centroid dengan menggunakan rumus sebagai berikut:

$d_{(x, y)}=\sqrt{(x i-y i)^{2}+(x i-y i)^{2}}$

Keterangan:

$\mathrm{d}=$ titik dokumen

$\mathrm{x}=$ data record

$\mathrm{y}=$ data centroid

B. Kelompokkan setiap data berdasarkan jarak terpendek antar centroid dengan dokumen, untuk menentukkan posisi cluster suatu dokumen. Misalnya dokumen A mempunyai jarak yang paling dekat dengan centroid 1 dibanding dengan yang lain maka dokumen A masuk ke kelompok 1.

C. Hitung kembali posisi centroid baru untuk tiap tiap centroid $\left(\mathrm{C}_{\mathrm{i} . . . \mathrm{j}}\right)$ dengan cara menghitung nilai rata rata dokumen yang masuk pada cluster awal $\left(\mathrm{G}_{\mathrm{i} . . . \mathrm{j}}\right)$. rumus sebagai berikut:

$$
C(i)=\frac{X_{1}+X_{2}+X_{n}}{\sum x}
$$

Keterangan:

$\mathrm{X}_{1}=$ nilai data record $\mathrm{ke}-1$

$\mathrm{X}_{2}=$ nilai data record $\mathrm{ke}-2$

$\mathrm{X}_{\mathrm{n}}=$ nilai data record $\mathrm{ke}-\mathrm{n}$

$\sum x=$ jumlah data record

D. Ulangi langkah a,b,c hingga posisi centroid tidak berubah

\section{Dokumen Teks Pendek}

Jenis jenis dokumen menurut sifatnya ada 2 yaitu dokumen tekstual dengan dokumen nontekstual. Dokumen tekstual adalah menyajikan informasi dalam bentuk tulisan, contohnya jurnal, majalah, buku, dan sebagainya. Dokumen teks pendek termasuk jenis dokumen tekstual. Menurut, dokumen teks pendek adalah dokumen yang berisi tidak lebih dari 100 kata, contohnya pada setiap paragraf abstrak ilmiah, dan tweet pada twitter (Mika Timonen,dkk., 2012). Menurut buku pedoman skripsi Jurusan Teknik Elektro Fakultas Teknik UNJ(2012), abstrak merupakan tulisan singkat menyeluruh dari isi skripsi/KI/komprehensif sehingga dengan membaca abstrak pembaca dapat menilai isi nya dengan cepat karena abstrak berisi pokok masalah, tujuan, metode penelitian, hasil penelitian dan kesimpulan. Panjang abstak maksimal 1 halaman berjumlah 200 kata (lebih kurang 20 kalimat). 


\section{Metodologi}

Metode penelitian yang digunakan adalah metode eksperimen.

Langkah langkah penelitian

A. Pengumpulan Data

pengelompokkan abstrak berdasarkan kelompok ini akan dipakai 4 data yang berbeda. Data pertama adalah abstrak ilmiah di jurusan Teknik Elektro, Universitas Negri Jakarta pada paragraf 1 sampai paragraf 3. Data kedua adalah paragraf 1 pada abstrak ilmiah di jurusan Teknik Elektro, Universitas Negri Jakarta. Data ketiga adalah paragraf 2 pada abstrak ilmiah di jurusan Teknik Elektro, Universitas Negri Jakarta. Data keempat adalah paragraf 3 pada abstrak ilmiah di jurusan Teknik Elektro, Universitas Negri Jakarta. Setelah itu data diubah format nya menjadi .txt.

B. Pengelompokkan Secara Manual

Setelah data dibagi bagi maka data di kelompokkan dahulu sacara manual dengan berdasarkan 2 cluster yaitu pendidikan dan non pendidikan. Pengelompokkan berdasarkan pendidikan memiliki keyword yang dapat memudahkan untuk proses pengelompokkan secara manual. Keywordnya seperti siswa/peserta didik, pembelajaran, pengajar/guru. Kalau pengelompokkan berdasarkan non pendidikan juga memiliki keyword dan keywordnya adalah selain dari keyword pengelompokkan pendidikan. Setelah di kelompokkan maka mendapatkan hasil 66 data pendidikan dan 134 data non pendidikan.

C. Pra Proses Data

Tahapan pra proses data, meliputi:

1. toLowerCase

Pada tahap toLowerCase, mengubah semua kata yang ada di setiap dokumen menjadi huruf kecil

2. Tokenisasi

Pada tahap tokenisasi ini, penguraian deskripsi yang semula berupa kalimatkalimat menjadi kata-kata dan menghilangkan delimiter-delimiter seperti tanda (.), koma(,), spasi dan karakter angka yang ada pada kata tesebut. Setiap dokumen dan query direpresentasikan dengan model bagof-words

D. Feature Selection

Setelah selesai dengan tahap pra proses data maka kata kata yang tidak deskriptif dapat dihilangkan dalam pendekatan bag- of-words di sebut juga stopword . Contoh stopword adalah dan, atau, yang, adalah, yaitu.

E. Membuat Vector Space Model

Setelah menghilangkan stopword pada setiap dokumen, kemudian tahap berikutnya membuat vector space model. Pembuatan vector space model, yaitu mengumpulkan kata pada semua dokumen, kemudian mencari document frequency setiap kata pada document, kemudian menghitung invers document frequency dengan cara menggunakan rumus sebagai berikut:

$$
i d f=\log \frac{\text { total document }}{\text { document frequency }}
$$

kemudian mencari term frequency setiap kata per document, term frequency ini didapatkan dari banyaknya per kata per dokumen,

$$
T F=\text { Jumlah kata per dokumen }
$$

setelah itu mencari TFIDF(Term Frequency Invers Document Frequency) dengan cara menggunakan rumus sebagai berikut:

$\operatorname{TFIDF}(w, d)=\operatorname{TF}(w, d) \times\left(1+\left(\log \left(\frac{N}{D F(w)}\right)\right)\right)$

Setelah melakukan tahap pembutan vector space model maka normalkan dengan cara persamaan sebagai berikut

$\operatorname{Normal}(i)=\frac{\operatorname{TFIDF}(i)}{\sqrt{\operatorname{TFIDF}(i)^{2}+\operatorname{TFIDF}(i+1)^{2}+\cdots+T F I D F(i+n)^{2}}}$

F. Mengurangi Dimensi

Setelah data sudah dinormalkan maka data terlebih dahulu di PCA(Principal Componen Analysis), untuk mendapatkan principal component pada matlab adalah dengan menggunakan fungsi princomp yang telah disiapkan pada statics toolbox. Pada fungsi princomp akan menghitung eigen function dari covarians dan menghasilkan tiga buah variabel, yaitu coeffisien, score dan latent.

$[$ Coeff Score Latent $]=\operatorname{princomp}($ data yang di input $)$ Keterangan

Coeffisien : menyimpan nilai koefisien dari principal component

Latent : menyimpan varians dari principal component

Score : data principal componen dari data yang di input yang telah di urutkan dari baris pertama sampai baris terakhir, dimana baris pertama mengandung informasi data (principal component) yang 
paling penting pertama, kemudian paling penting nomor 2 berada di baris kedua dan seterusnya hingga baris terakhir yang merupakan data yang kurang berarti.

Setelah di princomp ambil 2 data pertama dari hasil coeffisien. Kemudian dikali dengan data yang yang sudah dinormalkan.

\section{G. Algoritma Kmeans++}

Setelah tahap mengurasi dimensi kemudian selanjutnya langkah berikutnya data dapat di cluster dengan menggunakan algoritma k-means++. Langkah langkah clustering dengan algoritma k-means ++ sebagai berikut

A. Memilih centroid awal dengan cara memilih $k_{i}$ secara acak setelah itu memilih $k_{i+1}$ dengan cara menggunakan weighted propability distribution, dengan menggunakan rumus : $\frac{D(x)^{2}}{\sum x \in X^{D(x)^{2}}}$ Setelah itu cari data dengan probabilitas tertinggi, sampai sejumlah $k$ centroids telah terpilih.

B. Kemudian hitung iterasi dengan menggunakan rumus sebagai berikut:

$d_{(x, y)}=\sqrt{\left(x_{1}-\mathrm{y}_{1}\right)^{2}+\left(x_{2}-\mathrm{y}_{2}\right)^{2}}$

Keterangan:

$\mathrm{d}=$ titik dokumen

$\mathrm{x}=$ data record

$\mathrm{y}=$ data centroid

C. Kelompokkan setiap data berdasarkan jarak terpendek antar centroid dengan dokumen, untuk menentukkan posisi cluster suatu dokumen.

D. Hitung kembali posisi centroid baru untuk tiap-tiap centroid $\left(\mathrm{C}_{\mathrm{i} . . . \mathrm{j}}\right)$ dengan cara menghitung nilai rata rata dokumen yang masuk pada cluster awal $\left(\mathrm{G}_{\mathrm{i} . . . \mathrm{j}}\right)$. rumus sebagai berikut:

Keterangan:

$$
C(i)=\frac{x 1+x 2+x \ldots+x_{n}}{\sum x}
$$

$\mathrm{X}_{1}=$ nilai data record $\mathrm{ke}-1$

$\mathrm{X}_{2}=$ nilai data record $\mathrm{ke}-2$

$\sum x=$ jumlah data record

E. Ulangi langkah b,c,d hingga posisi centroid tidak berubah, yaitu titik centroid sama dengan titik sebelumnya.

\section{Hasil dan Analisis}

Tabel 6.1 Pengukuran pada abstrak

\begin{tabular}{|c|l|c|c|c|}
\hline \multicolumn{4}{|c|}{ Predicted Class } & \multirow{2}{*}{ Total } \\
\hline \multirow{2}{*}{$\begin{array}{c}\text { Actual } \\
\text { Class }\end{array}$} & Non Pendidikan & 133 & 20 & 153 \\
\cline { 2 - 4 } & Pendidikan & 1 & 46 & 47 \\
\hline \multicolumn{2}{|c|}{ TOTAL } & 134 & 66 & 200 \\
\hline
\end{tabular}

Berdasarkan tabel 4.5 ,didapatkan data berupa matriks untuk mengukur nilai akurasi, presisi dan recall pada abstrak setiap kategori. Perhitungan untuk akurasi, presisi dan recall adalah

Akurasi $=\frac{133+46}{200}=0,90$

Presisi Non Pendidikan $=\frac{133}{134}=0,99$

Presisi Pendidikan $=\frac{46}{66}=0,70$

Recall Non Pendidikan $=\frac{133}{153}=0,87$

Recall Pendidikan $=\frac{46}{47}=0,98$

Tabel 6.2 Pengukuran pada paragraf 1 abstak

\begin{tabular}{|c|l|c|c|c|}
\hline \multicolumn{4}{|c|}{ Predicted Class } & \multirow{2}{*}{ TOTAL } \\
\hline \multirow{2}{*}{$\begin{array}{c}\text { Actual } \\
\text { Class }\end{array}$} & & Non Pendidikan & Pendidikan & \\
\cline { 2 - 4 } & Non Pendidikan & 127 & 18 & 145 \\
\cline { 2 - 4 } & Pendidikan & 7 & 48 & 55 \\
\hline \multicolumn{2}{|c|}{ TOTAL } & 134 & 66 & 200 \\
\hline
\end{tabular}

Berdasarkan tabel 4.6 ,didapatkan data berupa matriks untuk mengukur nilai akurasi paragraf 1 pada abstrak, presisi dan recall paragraf 1 pada abstrak setiap kategori. Perhitungan untuk akurasi, presisi dan recall adalah

$$
\begin{aligned}
& \text { Akurasi }=\frac{127+48}{200}=0,88 \\
& \text { Presisi Non Pendidikan }=\frac{127}{134}=0,95 \\
& \text { Presisi Pendidikan }=\frac{48}{66}=0,73 \\
& \text { Recall Non Pendidikan }=\frac{127}{145}=0,88 \\
& \text { Recall Pendidikan }=\frac{48}{55}=0,87
\end{aligned}
$$

Tabel 6.3 Pengukuran pada paragraf 2 abstrak

\begin{tabular}{|c|l|l|l|l|}
\hline \multicolumn{3}{|c|}{ Predicted Class } & \multirow{2}{*}{ TOTAL } \\
\hline \multirow{2}{*}{$\begin{array}{c}\text { Actual } \\
\text { Class }\end{array}$} & Non Pendidikan & 133 & Pendidikan & \\
\cline { 2 - 5 } & Pendidikan & 1 & 32 & 165 \\
\hline \multicolumn{2}{|c|}{ TOTAL } & 134 & 34 & 35 \\
\hline
\end{tabular}

Berdasarkan tabel 4.7 ,didapatkan data berupa matriks untuk mengukur nilai akurasi, presisi dan recall paragraf 2 pada abstrak setiap kategori. Perhitungan untuk akurasi, presisi dan recall adalah

Akurasi $=\frac{133+34}{200}=0,84$

Presisi Non Pendidikan $=\frac{133}{134}=0,99$

Presisi Pendidikan $=\frac{34}{66}=0,51$

Recall Non Pendidikan $=\frac{133}{165}=0,81$

Recall Pendidikan $=\frac{34}{35}=0,97$

Tabel 6.4 Pengukuran pada paragraf 3 abstrak

\begin{tabular}{|c|c|c|c|c|}
\hline \multicolumn{3}{|c|}{ Predicted Class } & \multirow{2}{*}{ TOTAL } \\
\hline \multirow{2}{*}{$\begin{array}{c}\text { Actual } \\
\text { Class }\end{array}$} & Non Pendidikan & Pendidikan & \\
\cline { 2 - 5 } & Non Pendidikan & 132 & 17 & 149 \\
\cline { 2 - 4 } & Pendidikan & 2 & 49 & 51 \\
\hline \multicolumn{2}{|c|}{ TOTAL } & 134 & 66 & 200 \\
\hline
\end{tabular}

Berdasarkan tabel 4.8 ,didapatkan data berupa matriks untuk mengukur nilai akurasi, presisi dan recall paragraf 3 pada abstrak setiap kategori. 
Perhitungan untuk akurasi, presisi dan recall adalah

Akurasi $=\frac{49+132}{200}=0,91$

Presisi Non Pendidikan $=\frac{132}{134}=0,99$

Presisi Pendidikan $=\frac{49}{66}=0,74$

Recall Non Pendidikan $=\frac{132}{149}=0,89$

Recall Pendidikan $=\frac{49}{51}=0,96$

\section{Kesimpulan dan Saran}

\subsection{KESIMPULAN}

Berdasarkan hasil penelitian, didapatkan akurasi pada abstrak sebesar $90 \%$, akurasi pada paragraf 1 di abstrak sebesar $88 \%$, akurasi pada paragraf 2 di abstrak sebesar $84 \%$, akurasi pada paragraf 3 di abstrak sebesar 91\%. Jadi tingkat akurasi yang baik adalah pada paragraf 3 di abstrak skripsi Jurusan Teknik Elektro Fakultas Teknik UNJ sebesar 91\%. Walaupun menurut D.manning and Hinrich schutze mengatakan kemunculan kata hanya 1 kali disebut hapax legomena. Pada penelitian ini terjadi di setiap dokumen kemunculan kata hanya 1 kali dan itulah kekurangan dari dokumen teks pendek akan tetapi dengan algoritma kmeans++ untuk pengelompokkan teks pendek mempunyai keakurasian diatas $80 \%$ dan presisi diatas $50 \%$ dan recall diatas $80 \%$. Jadi pengelompokkan teks pendek mempunyai akurasi, presisi dan recall yang tinggi. Maka kesimpulannya, pengelompokkan pada dokumen teks pendek dengan menggunakan algoritma kmeans ++ baik untuk 2 cluster yaitu pendidikan dan non pendidikan untuk hanya di Jurusan Teknik Elektro Fakultas Teknik UNJ.

\subsection{SARAN}

Berdasarkan penelitian dapat dikemukkan saran, yaitu memperhatikan cara penulisan pada abstrak skripsi di Jurusan Teknik Elektro Fakultas Teknik UNJ, untuk penelitian selanjutnya dapat menambahkan $\mathrm{k}$ nya dan jika $\mathrm{k}$ ingin ditambah maka data harus di tambah dan jika penelitian ini dilanjutkan maka harus menggunakan algoritma lain dalam proses pengelompokkannya.

\section{Daftar Pustaka:}

Adi Wibowo, d. (2013). Implementasi Generalized Vector Space Model Menggunakan WordNet.
Adiningsih,E.S.; Mahmud; Effendi,I. (2004). Aplikasi Analisis Komponen Utama Dalam Pemodelan Penduga Lengas Tanah Dengan Data Satelit Multi Spektral. Matematika dan Sains , 215-222.

Amalia Indranandita, d. (2008). Sistem Klasifikasi dan Pencarian Jurnal dengan Menggunakan Metode Naive Bayes dan Vector Space Model. Informatika, 9-18.

Amin, f. (2011). Implementasi Search Engine(mesin pencari) Menggunakan Metode Vector Space Model. Dinamika Teknik, 45-58.

Andayani, S. (2007). Pembentukan Cluster dalam Knowledge Discovery in Database dengan Algoritma k-means.

Arthur, D., \& Vassilvitskii. (2007). Kmenas $++:$ The advantages of Careful Seeding.

Brammer, M. (2007). Principlesd of Data Mining. londong: Springer.

Christopher, D. M., \& Hinrich, S. (1999). Foundations of Statistical Natural Language Processing. London: Cambridge University Press.

Dragut, E., Fang, F., Sistla, P., Yu, S., \& Meng, w. (2009). Stop Word and Rekated Problem in WebInterfac Integration.

Feldman, R., \& Sanger, J. (2007). The Text Mining Handbook. New York: cambridge University Press.

Han, J., \& Kamber, M. (2006). Data Mining Concept and Tehniques. San Fransisco: Morgan Kauffman.

Intan,R.\&Defeng,A.2006.HARD:Subject Based Search Engine Menggunakan TFIDF dan Jaccard's Coefficient.https://puslit.petra.ac.id/jo urnals/pdf.php

Ismail Djakaria, d. (2010). Visualisasi Data Iris Menggunakan Analisis Komponen Utama dan Analisis Komponen Utama Kernel. Ilmu Dasar. 
Istiany, Ari.(2012).Buku Pedoman Skripsi Jurusan Teknik Elektro Fakultas Teknik UNJ. Jakarta: UNJ.

Karandikar, A. (2010). Clustering Short Status Message A Topuc Model BAsed Approach.

Kumar, R., \& Mathur, R. P. (2014). Short Text Clustering Using Numeric Data Based on N-gram. IEEE , 274-276.

Kurniawan,B; Effendi,S; Sitompul,O.S. (2012). Klasifikasi Konten Berita dengan Metode Text Mining. Dunia Teknologi Informasi , 14-19.

Manning, C., Raghavan, p., \& Schutze, H. (2008). Introduction of Information Retrieval . New York: Cambridge University Press.

Oktafia, D., dan Pardede, D.L.C., 2010, Perbandingan Kinerja Algoritma Decision Tree dan Naïve Bayes dalam Prediksi Kebangkrutan, Proceeding Seminar Ilmiah Nasional KOMMIT 2010, Universitas Gunadarma

Poerwadarminta, W. (2007). Kamus Umum Bahasa Indonesia.

RENIER, G.J (1997). History its purpose and Method. Yogyakarta: Pustaka Pelajar.

Santoso, B. (2007). Data Mining: Teknik PemamfaatanData untuk Keperluan Bisnis. Yogyakarta: Graha Ilmu.

Simanjuntak, P.J. 2005. Manajemen dan Evaluasi Kerja. Lembaga Penerbit FEUI, Jakarta.

Setiawan, E. (2012). Kamus Besar Bahasa Indonesia Online. KEMDIKBUD.

Shrestha, P., Jacquin, C., \& Daille, B. (2012). Clustering Short Text and Its Evaluation. A. Gelbukh (Ed.): CICLing, 169-180.

Smith,L.I.A Tutorial on Principal Component Analysis.Internet: http://www.csotago.ac.nz/cosc453/stu dent_tutorials/principal_component.p df,[19 Juni 2015]

Swastina, L. (2013). Penerapan Algoritma C4.5 Untuk Penentuan Jurusan Mahasiswa. Gema Aktualita , 93-98.
Timonen, M., Toivanen, T., Kasari, M., Teng, Y., Cheng, C., \& He, L. (2012). Keyword Extraction from Short Documents Using Three Levels of Word Evaluation. knowledge Discovery, Knowledge Engineering and Knowledge Management , 130146.

Wayan surya priantara, d. (2011). Implementasi Deteksi Penjiplakan dengan Algoritma Winnowing pada Dokumen Terkelompok. Seminar Tugas Akhir , 1-9.

Wibowo. 2007. Manajemen Kinerja : Jakarta : Raja Grafindo Persada.

Weiss, S., Indurkhya, n., zhang, T., \& Damerau, F. (2005). Text Mining: Predictive Methode to Analyzing Unstructed Information. New York: Springer 